\title{
Porcine reproductive and respiratory syndrome virus (PRRSV)
} infection spreads by cell-to-cell transfer in cultured MARC- I 45 cells, is dependent on an intact cytoskeleton, and is suppressed by drug-targeting of cell permissiveness to virus infection William A Cafruny*1, Richard G Duman², Grace HW Wong3 ${ }^{3}$, Suleman Said ${ }^{4}$, Pam Ward-Demo ${ }^{5}$, Raymond RR Rowland ${ }^{6}$ and Eric A Nelson ${ }^{7}$

Address: ${ }^{1}$ Division of Basic Biomedical Science, Sanford School ofMedicine, University of South Dakota, Vermillion, SD 57069, USA, ${ }^{2}$ Division of Basic Biomedical Sciences, Sanford School ofMedicine, University of South Dakota, Vermillion, SD 57069, USA, ${ }^{3}$ Actokine Therapeutics, 12 Middlesex Rd. Chestnut Hill, MA02467, USA, ${ }^{4}$ Division of Basic Biomedical Sciences, Sanford School ofMedicine, University of South Dakota, Vermillion, SD 57069, USA, 5Sanford School of Medicine, University of South Dakota, Vermillion, SD 57069, USA, ${ }^{6}$ Department of Diagnostic Medicine and Pathobiology, KansasState University, Manhattan, KS 66506, USA and ${ }^{7}$ Department of Veterinary Science, South Dakota State University, Brookings, SD 57007, USA

Email: William A Cafruny* - bcafruny@usd.edu; Richard G Duman - rduman@usd.edu; Grace HW Wong - gw@actokine.com; Suleman Said - ssaid@usd.edu; Pam Ward-Demo - pwarddem@usd.edu; Raymond RR Rowland - browland@vet.ksu.edu; Eric A Nelson - Eric.Nelson@sdstate.edu

* Corresponding author

Published: 02 November 2006

Virology Journal 2006, 3:90 doi:10.1186/1743-422X-3-90
Received: 15 June 2006

Accepted: 02 November 2006

This article is available from: http://www.virologyj.com/content/3/I/90

(C) 2006 Cafruny et al; licensee BioMed Central Ltd.

This is an Open Access article distributed under the terms of the Creative Commons Attribution License (http://creativecommons.org/licenses/by/2.0), which permits unrestricted use, distribution, and reproduction in any medium, provided the original work is properly cited.

\begin{abstract}
Background: Porcine reproductive and respiratory syndrome virus (PRRSV) is the etiologic agent of PRRS, causing widespread chronic infections which are largely uncontrolled by currently available vaccines or other antiviral measures. Cultured monkey kidney (MARC-I45) cells provide an important tool for the study of PRRSV replication. For the present study, flow cytometric and fluorescence antibody (FA) analyses of PRRSV infection of cultured MARC-I 45 cells were carried out in experiments designed to clarify viral dynamics and the mechanism of viral spread. The roles of viral permissiveness and the cytoskeleton in PRRSV infection and transmission were examined in conjunction with antiviral and cytotoxic drugs.

Results: Flow cytometric and FA analyses of PRRSV antigen expression revealed distinct primary and secondary phases of MARC145 cell infection. PRRSV antigen was randomly expressed in a few percent of cells during the primary phase of infection (up to about 20-22 h p.i.), but the logarithmic infection phase (days 2-3 p.i.), was characterized by secondary spread to clusters of infected cells. The formation of secondary clusters of PRRSV-infected cells preceded the development of CPE in MARC-I45 cells, and both primary and secondary PRRSV infection were inhibited by colchicine and cytochalasin D, demonstrating a critical role of the cytoskeleton in viral permissiveness as well as cell-to-cell transmission from a subpopulation of cells permissive for free virus to secondary targets. Cellular expression of actin also appeared to correlate with PRRSV resistance, suggesting a second role of the actin cytoskeleton as a potential barrier to cell-to-cell transmission. PRRSV infection and cell-to-cell transmission were efficiently suppressed by interferon- $\gamma$ (IFN- $\gamma$ ), as well as the more-potent experimental antiviral agent AK-2.

Conclusion: The results demonstrate two distinct mechanisms of PRRSV infection: primary infection of a relatively small subpopulation of innately PRRSV-permissive cells, and secondary cell-to-cell transmission to contiguous cells which appear nonpermissive to free virus. The results also indicate that an intact cytoskeleton is critical for PRRSV infection, and that viral permissiveness is a highly efficient drug target to control PRRSV infection. The data from this experimental system have important implications for the mechanisms of PRRSV persistence and pathology, as well as for a better understanding of arterivirus regulation.
\end{abstract}




\section{Background}

Porcine reproductive and respiratory syndrome virus (PRRSV) is an arterivirus which is the etiologic agent of PRRS, a disease of epidemic proportions in swine [1-3]. PRRSV is macrophage-tropic in vivo, where it establishes a chronic infection, and the virus replicates in primary pig macrophages in vitro [4-6]. PRRSV infection has been extensively studied in MARC-145 cells, a PRRSV-permissive monkey kidney cell line $[7,8]$. Previous studies have established that PRRSV replication in cultured MARC-145 cells follows a complex time-course, with PRRSV antigens becoming detectable by immunofluorescence analysis between about 10-20 h p.i., and emergence of foci of damage (cytopathic effect; CPE) usually over the next 3-4 days $[7,8]$.

The fate of PRRSV-infected MARC-145 cell cultures may include death of some cells by modified apoptosis [9] or necrosis [10], as well as establishment of chronic PRRSV infection (Cafruny \& Rowland, unpublished). Thus, clarifying the behavior of PRRSV in MARC-145 cells is significant to progress in developing anti-viral strategies.

Previous studies have suggested that initial defenses against PRRSV are comprised of innate lung and alveolar macrophage responses [6]; subsequently, both Th1 and Th2 responses are induced in the respiratory tracts of PRRSV-infected pigs [11]. PRRSV infection of pigs is associated with activation of several cytokines including interferon- $\gamma$ [IFN- $\gamma$; $[12,13]]$, which has PRRSV-inhibitory activity in vitro [14]. However, the IFN- $\gamma$ response to PRRSV may be inhibited or delayed by some unknown factors during PRRSV infection or vaccination $[15,16]$, and ultimately a poorly-neutralizing Th2-dependent response seems to result in many pigs. Combined, the characteristics of these host responses may facilitate viral persistence $[15,16]$.

The interaction of PRRSV with host cytokines is not well understood, but this area of study is a potential key to understanding host mechanisms during infection. Cytokines have not yet been exploited to control PRRSV infection in vivo, but their potential to regulate PRRSV infection in certain experimental systems provides a rationale for PRRSV discovery research, and anti-PRRSV agents may be important tools for future drug development.

The viral dynamics of another arterivirus, lactate dehydrogenase-elevating virus (LDV), are dominated by regulation of the LDV-permissive state; only a small fraction of mouse macrophages are susceptible to LDV infection, leading to an avirulent chronic infection in most mice which is maintained through development of newly-permissive cells [17]. Viral permissiveness is a logical but poorly exploited target for antiviral drugs [18-20], and the present study utilized two antiviral agents which target permissiveness (IFN- $\gamma$ and an experimental antiviral known as AK-2), as well as cytoskeleton disruptors, to probe checkpoints in PRRSV replication.

Initially, our goal was to better characterize the dynamics of PRRSV replication in MARC-145 cells. Using flow cytometry and fluorescence microscopy, we demonstrated logarithmic growth of PRRSV in MARC-145 cells, culminating over a period of 3-4 days in the death of most cells. Secondary spread of PRRSV infection was observed to be via cell-to-cell transmission, as demonstrated by emergence of clusters of PRRSV-infected cells in confluent monolayers of MARC-145 cells, which preceded PRRSVinduced CPE, were inhibited by colchicine and cytochalasin D, and correlated with reduced actin expression. PRRSV replication was sensitive to IFN- $\gamma$ as well as AK-2, which was a relatively more potent PRRSV inhibitor and capable of suppressing both primary and secondary PRRSV infection. The results of this study demonstrate cell-to-cell spread of PRRSV in cultured MARC-145 cells, the dependence of PRRSV infection and transmission on an intact cytoskeleton, and highlight the role of the PRRSV-permissive state as a critical drug target, with important implications for future therapeutic and preventive strategies.

\section{Results \\ PRRSV replication dynamics in MARC-I45 cells}

When PRRSV replication was assessed in MARC-145 cells at 20-22 h p.i., only a small proportion of cells expressed PRRSV antigen, as determined by FA $(<5 \%$ in $>10$ manual experiments counting fluorescent-positive cells under the microscope; Figure 1 by flow cytometry). However, between 42-72 h p.i. the percent of PRRSV-positive cells increased rapidly as determined by flow cytometric analyses, up to a maximum of about $95 \%$ by $96 \mathrm{~h}$ p.i. (Figures 1 \&2). Low permissiveness of MARC-145 cells to primary (less than about $22 \mathrm{~h}$ p.i.) PRRSV infection was not due to insufficient M.O.I., since inoculation of cultures with about 100-times the standard dose resulted in a maximum 5.5\% incidence of PRRSV-positive cells at $22 \mathrm{~h}$ p.i. by flow cytometry (data not shown). Propidium iodide staining followed by flow cytometry showed that PRRSV inoculated cells underwent major changes in cell cycle parameters (e.g. drop in G1 and G2; increased debris and aggregates) between 72-96 h p.i., consistent with cell damage and the spread of microscopic foci (CPE) typically observed throughout the cultures (data not shown).

FA analyses by confocal fluorescence microscopy, of dozens of independent PRRSV-infected confluent cultures, revealed that the primary $(<22 \mathrm{~h}$ p.i.) phase of PRRSV infection was characterized by random targeting of 

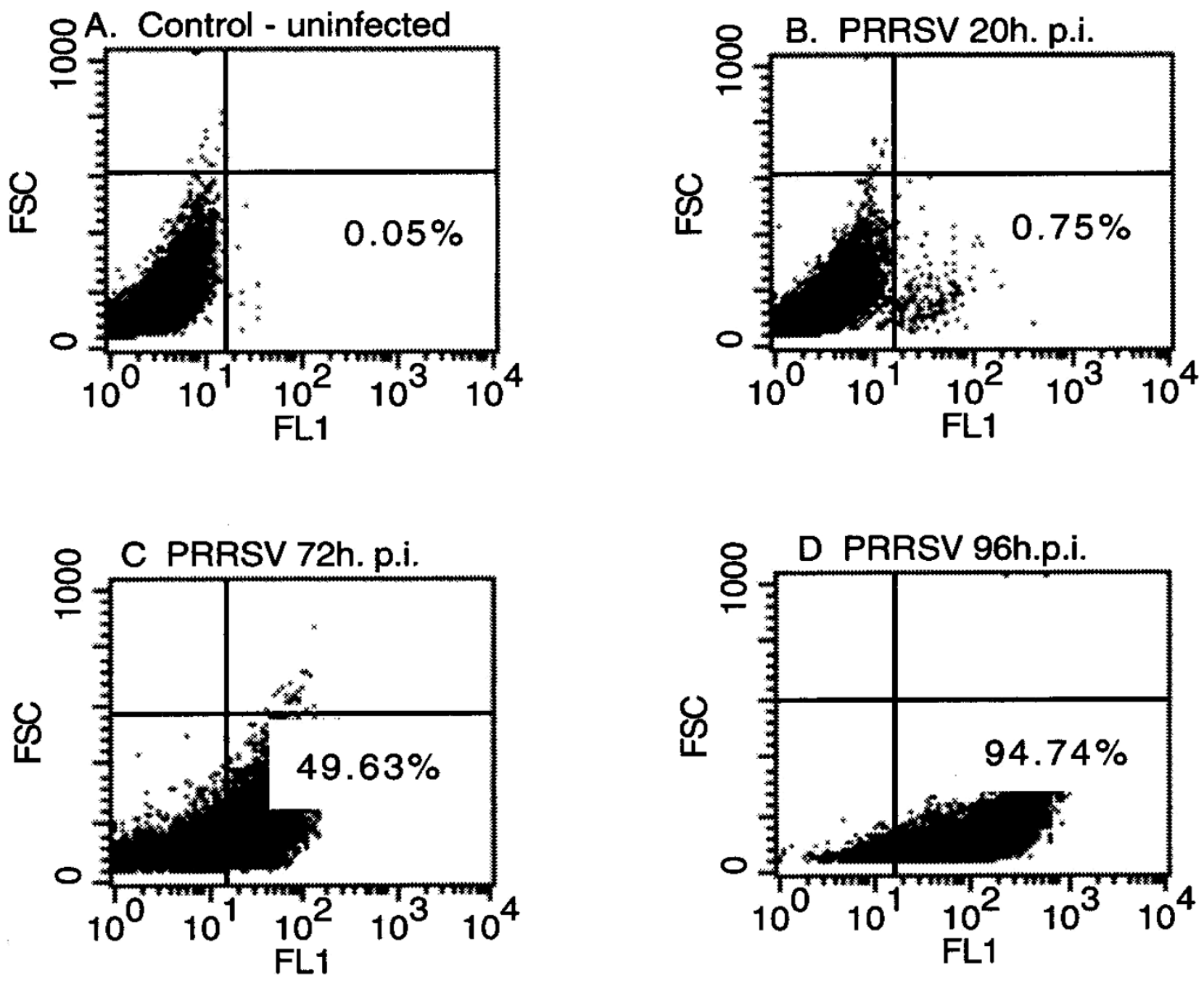

Figure I

PRRSV replication dynamics in MARC-I 45 cells by flow cytometry. A. Control (uninfected) cells; B. 20 h p.i. with PRRSV; C. $72 \mathrm{~h}$ p.i. with PRRSV; D. $96 \mathrm{~h}$ p.i. with PRRSV. The percentage of PRRSV antigen-positive cells is shown in the lower right quadrant for each graph.

PRRSV-permissive single cells (Figure 3A; see also Figure 5B for another example), representing only a few percent of the total cells, and consistent with the quantitative analyses by flow cytometry.

\section{Formation of PRRSV-infected cell clusters (secondary infection)}

During the logarithmic phase of viral replication (e.g. 42$48 \mathrm{~h}$ p.i.), infection was present mainly in clusters containing multiple PRRSV-positive MARC-145 cells, routinely observed against a PRRSV-negative background of confluent cells (examples indicated by arrows in Figures
3B,C,D; see also Figures 5C,D and 6B). These clusters were never observed in the primary infection analyses, although occasionally infected cell doublets were seen at 20-22 h p.i.. Based on $>10$ independent analyses, we estimate that about $90 \%$ of secondary PRRSV infection of MARC-145 cells line is characterized by formation of infected cell clusters.

Typically, dozens of clusters were seen in each culture, often containing a relatively central, bright-staining cell (e.g. Figure 3B,D), suggesting that cell-to-cell spread originated from a single PRRSV-infected reservoir cell. 

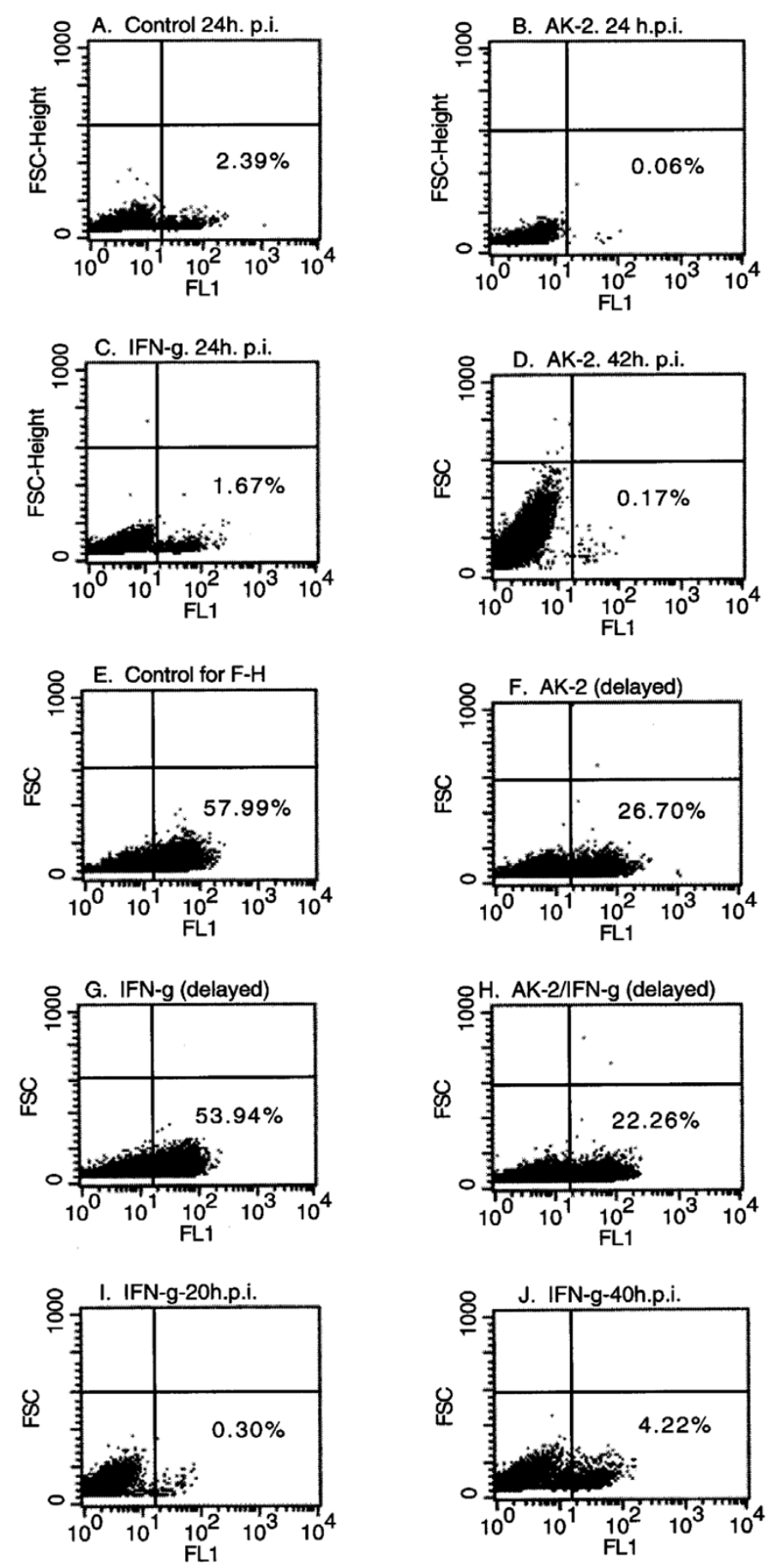

Figure 2

Effects of AK-2 and IFN- $\gamma$ on PRRSV replication in MARC- I 45 cells as determined by flow cytometry. A. Control 24 h p.i. with PRRSV; B. AK-2 pretreatment, 24 h p.i. with PRRSV; C. IFN- $\gamma$ pretreatment, 24 h p.i. with PRRSV; D. AK-2 pretreatment, 42 h p.i. with PRRSV; E. Control 46 h p.i. with PRRSV; F. AK-2 started at I8 h p.i. (delayed); G. IFN- $\gamma$ started at I8 h p.i. (delayed); H. AK-2 and IFN- $\gamma$ in combination, started at $18 \mathrm{~h}$ p.i.; I \& J. IFN- $\gamma$-pretreatment effects on primary (I) and secondary $(J)$ response PRRSV antigen detection. The percentage of PRRSV antigen-positive cells is shown in the lower right quadrant for each graph. 


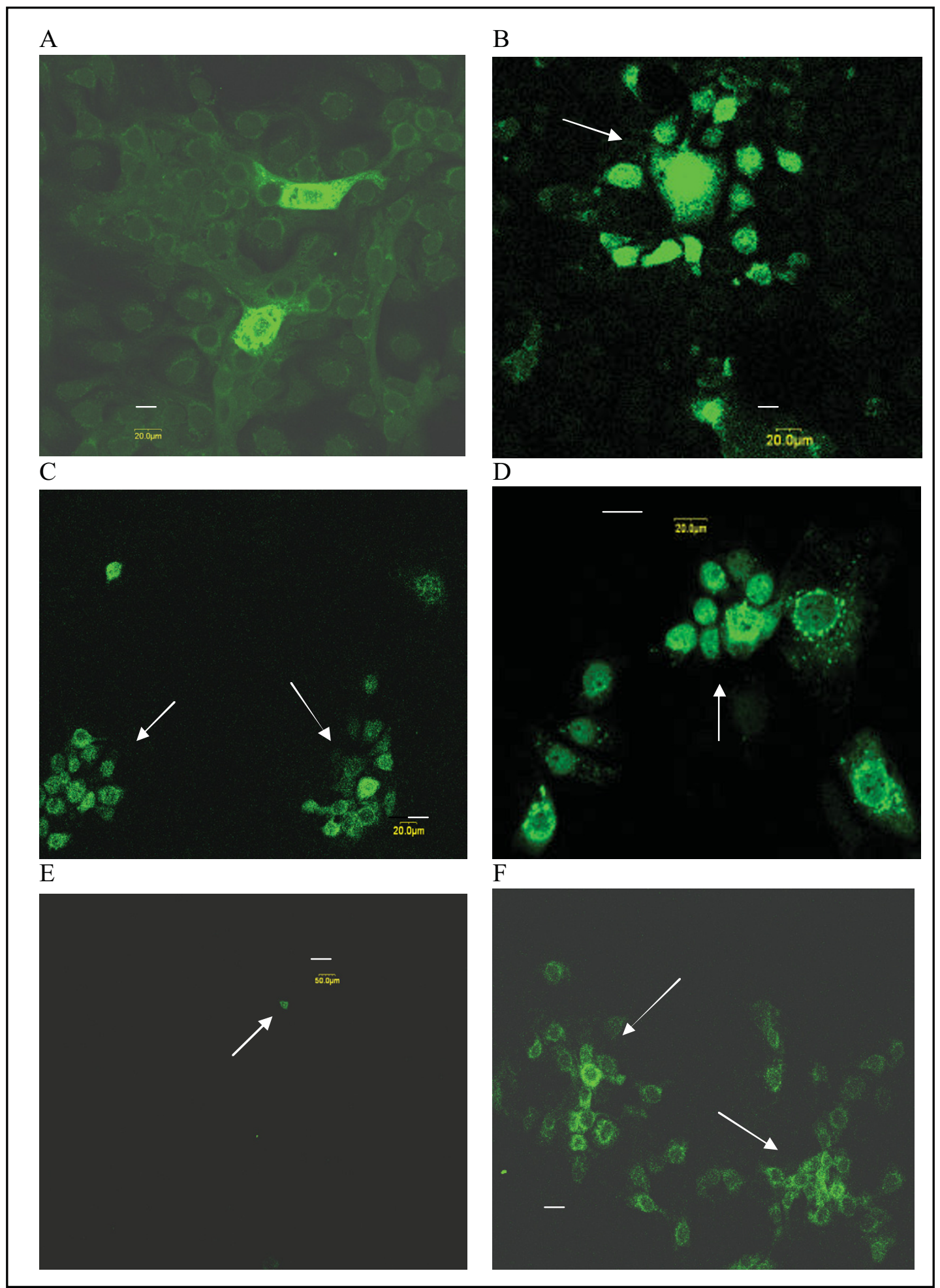

Figure 3

Confocal microscopy of FA-stained MARC-I 45 cells during PRRSV infection. A. 24 h p.i. with PRRSV, 20 um.; B-C. Secondary cluster formation (arrows) 42-46 h p.i. with PRRSV, $20 \mu \mathrm{m}$; D. Secondary cluster formation (arrow) $72 \mathrm{~h}$ p.i. with PRRSV, $20 \mu \mathrm{m}$.; E. AK-2 pretreatment, 42 h p.i.; arrow indicates a single PRRSV-positive cell, $50 \mu \mathrm{m}$; F. AK-2 post-treatment, $46 \mathrm{~h}$ p.i., arrows indicate several PRRSV-positive clusters, $20 \mu \mathrm{m}$. (Length of scale bar is indicated for each panel) 
A
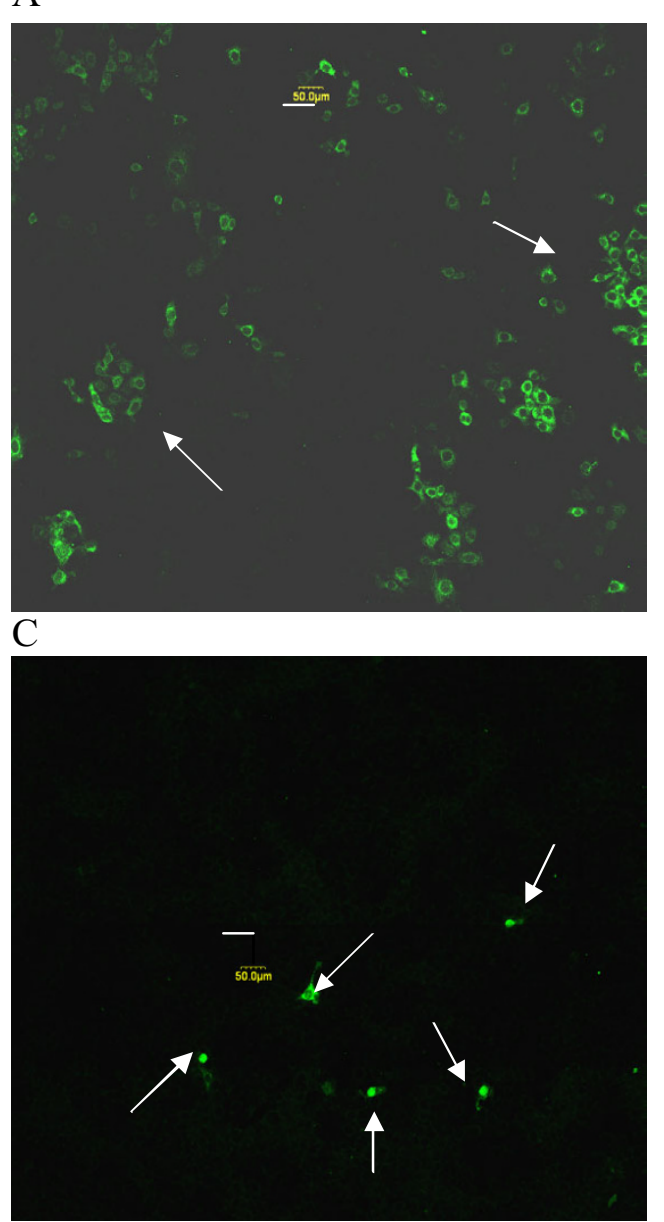

$\overline{\mathrm{E}}$

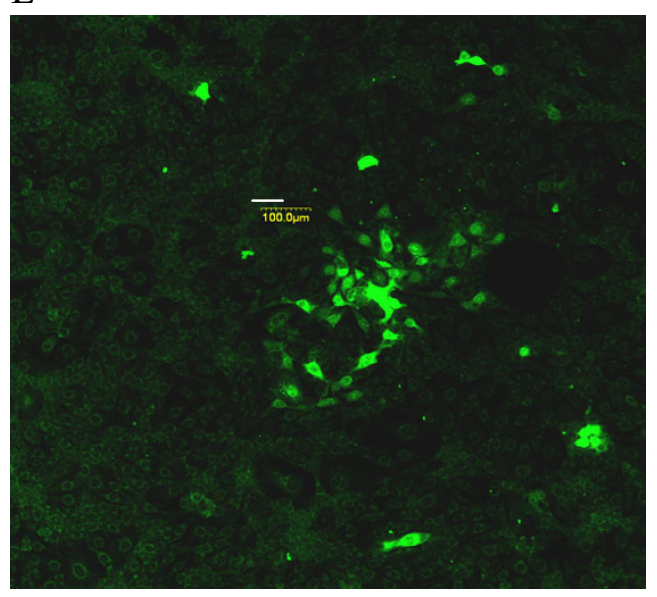

B

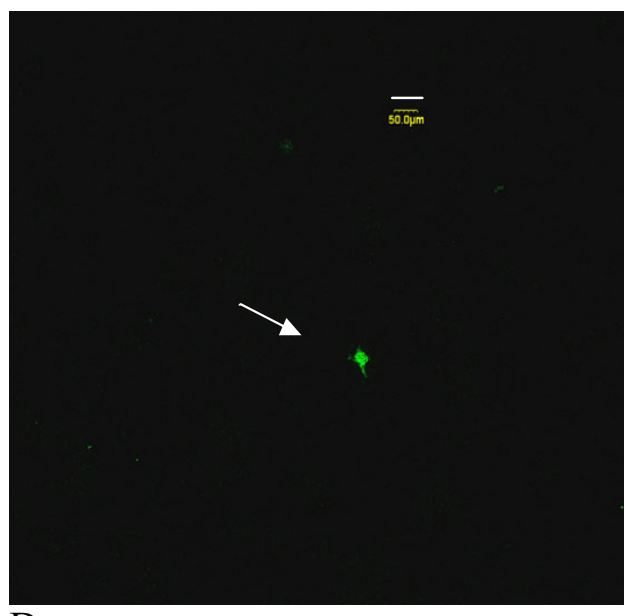

$\mathrm{D}$

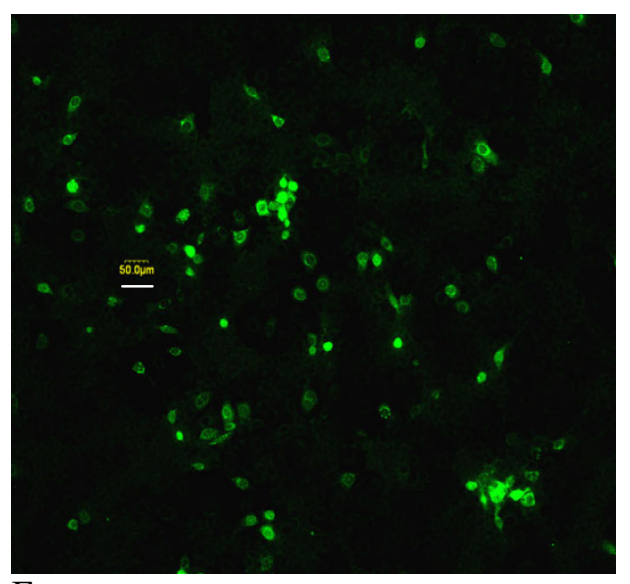

$\overline{\mathrm{F}}$

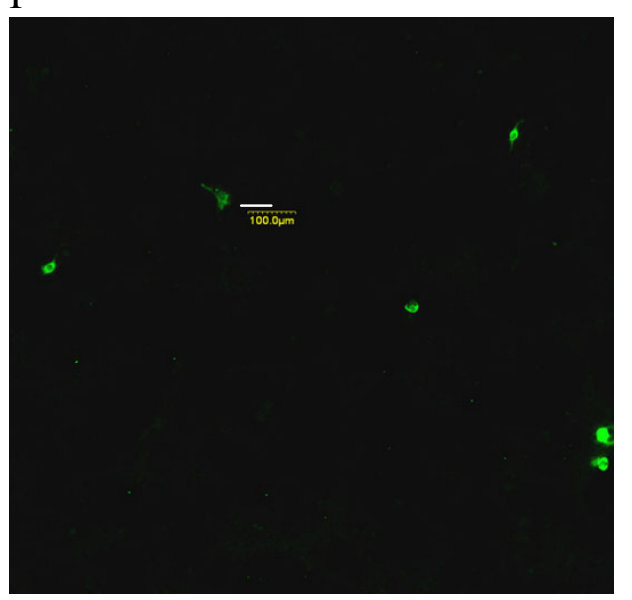

\section{Figure 4}

Confocal microscopy of FA-stained MARC-I 45 cells during PRRSV infection. A. IFN- $\gamma$ pretreatment, $46 \mathrm{~h}$ p.i., arrows indicate several PRRSV-positive clusters, $50 \mu \mathrm{m}$; B. AK-2 + IFN- $\gamma$ post-treatment, arrow indicates a single PRRSV-positive cell, $46 \mathrm{~h}$ p.i., $50 \mu \mathrm{m}$; C. AK-2 pretreatment, $42 \mathrm{~h}$ p.i., occasional PRRSV-positive cells (arrows), $50 \mu \mathrm{m}$; D. IFN- $\gamma$ pretreatment, $50 \mu \mathrm{m}$; E. $45 \mathrm{~h}$ p.i. with PRRSV, $100 \mu \mathrm{m}$; F. Simultaneous AK-2 treatment and PRRSV infection, $45 \mathrm{~h}$ p.i., $100 \mu \mathrm{m}$. (Length of scale bar is indicated for each panel) 
A

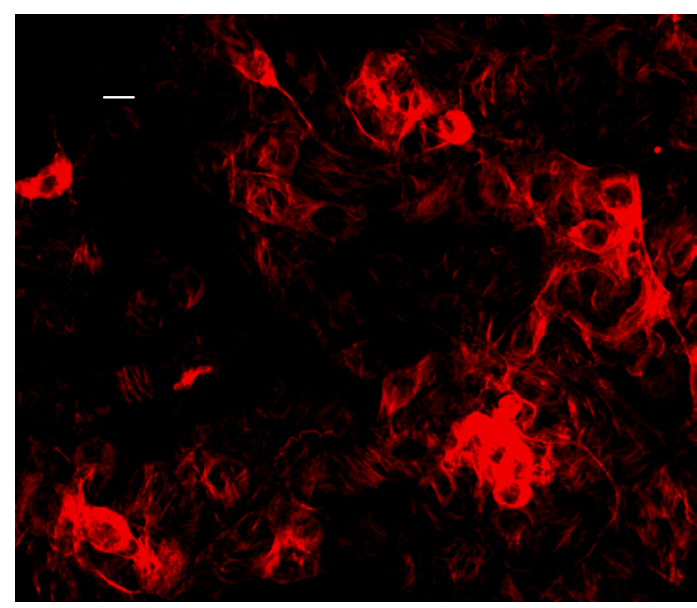

C

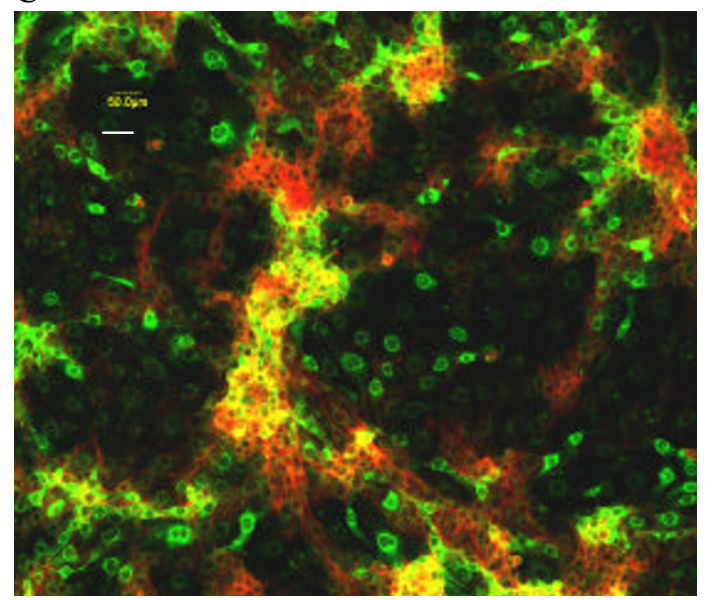

E

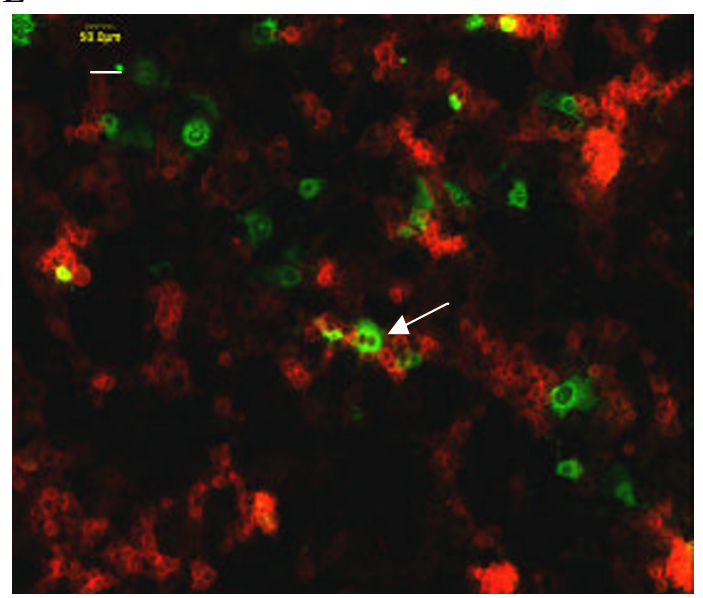

B

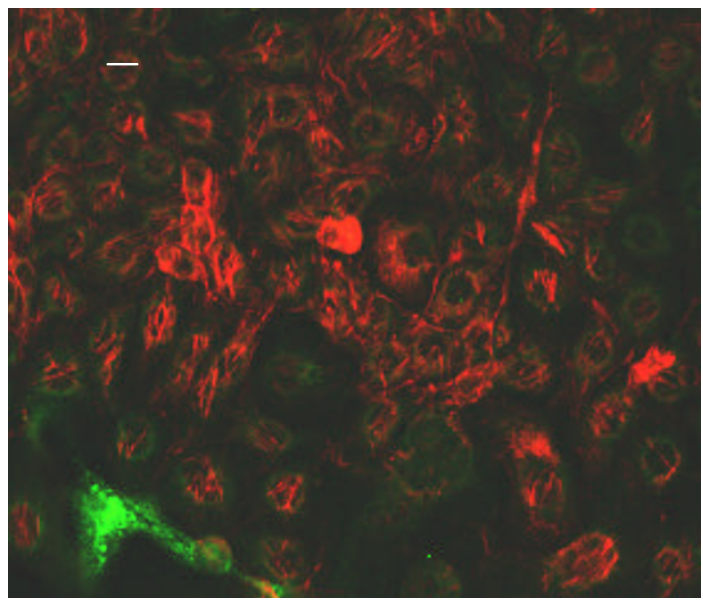

$\mathrm{D}$

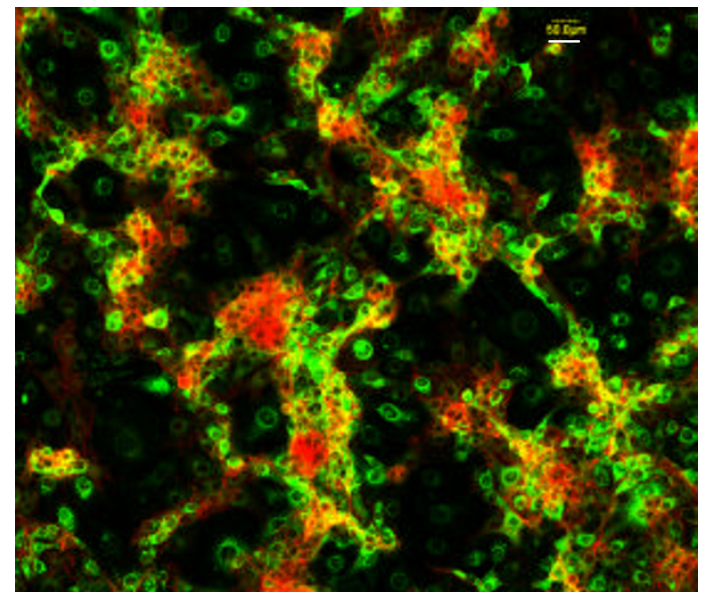

$\mathrm{F}$

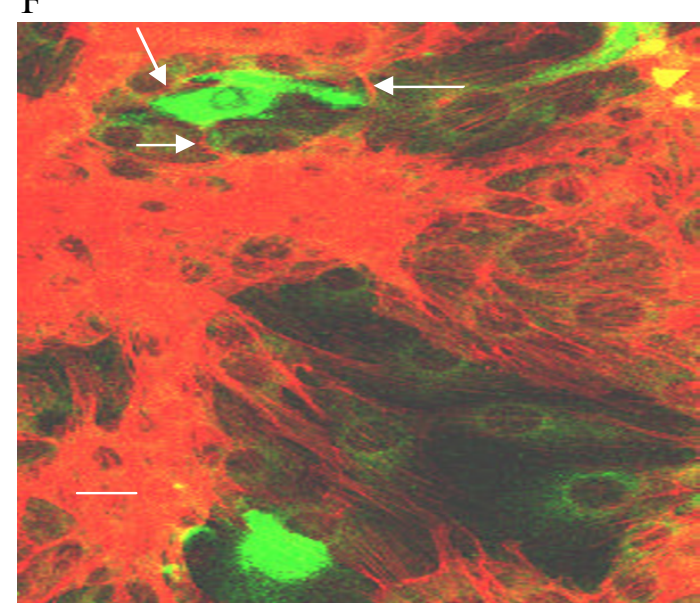

\section{Figure 5}

Two-color fluorescence detection of actin (red) and PRRSV antigen (green) in MARC-I45 cells. A. Uninfected control, $20 \mu \mathrm{m}$; B. I8 h p.i. with PRRSV, $20 \mu \mathrm{m}$; C. Control at 42 h p.i. with PRRSV, $50 \mu \mathrm{m}$; D. Drug vehicle control at 42 h p.i. with PRRSV, $50 \mu \mathrm{m}$. E. Colchicine-treated, $5 \mu \mathrm{M}, 42 \mathrm{~h}$ p.i. (arrow indicates PRRSV-positive doublet; see Figure 6, A, C and D for higher magnification), $50 \mu \mathrm{m}$; F. AK-2 treated, $250 \mu \mathrm{m}$; (Length of scale bar is indicated for each panel) 
A

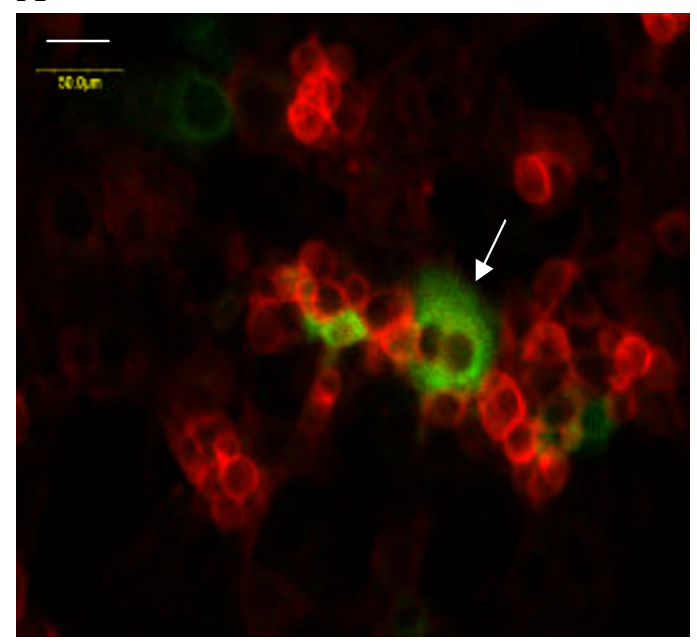

$\mathrm{C}$

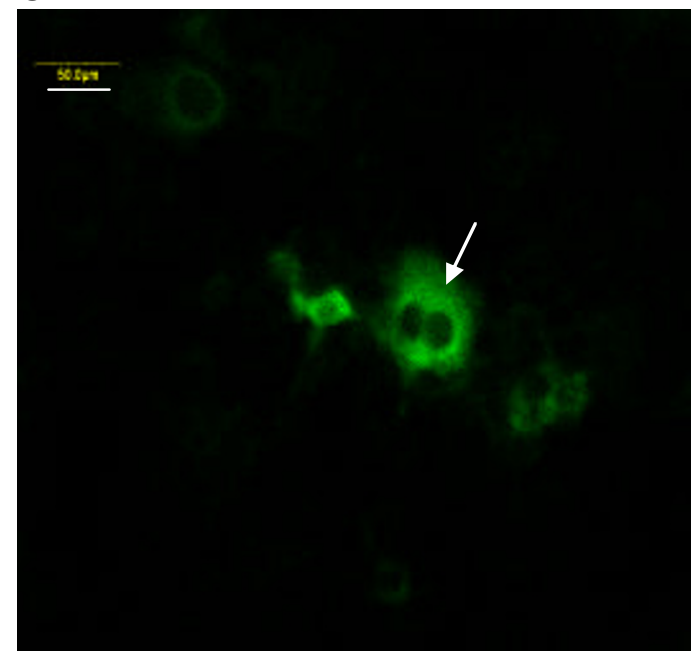

$\mathrm{E}$

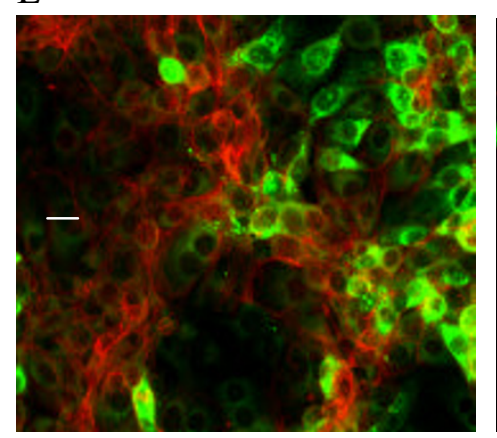

$\mathrm{B}$

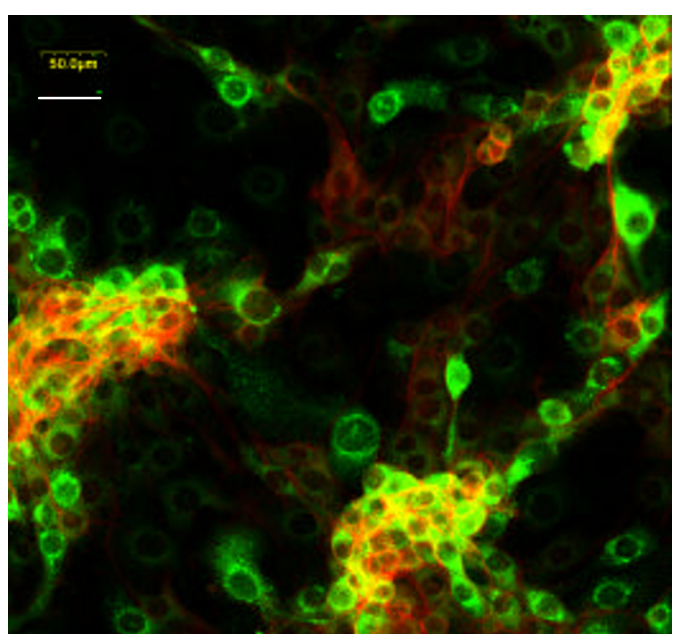

$\mathrm{D}$

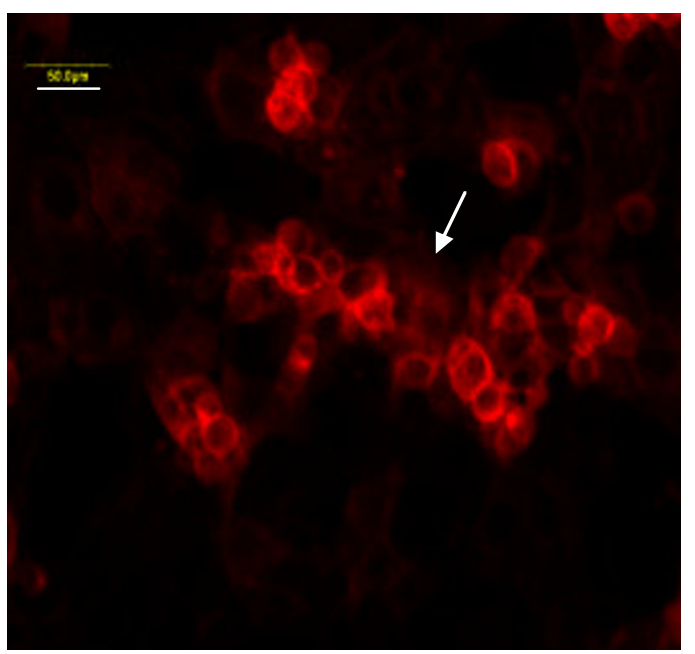

G

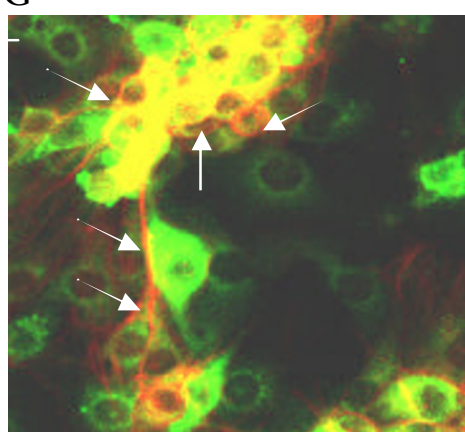

\section{Figure 6}

Two-color fluorescence detection of actin (red) and PRRSV antigen (green) in MARC-145 cells. A. PRRSVinfected cell doublet (arrow) in a colchicine-treated culture; higher magnification, $50 \mu \mathrm{m}$; B. Control - higher magnification, 50 $\mu \mathrm{m}$; C. Arrow indicates PRRSV-infected cell doublet; green-only (compare to red + green in A), $50 \mu \mathrm{m}$; D. Arrow indicates position of PRRSV-infected cell doublet, red-only (compare to red + green in A), $50 \mu \mathrm{m}$; E. Emerging clusters at $4 \mathrm{I}$ h p.i., 20 $\mu \mathrm{m}$; F. Cytochalasin D treatment $(I \mu \mathrm{M})$ at I $8 \mathrm{~h}$ p.i., $20 \mu \mathrm{m}$; G. control $42 \mathrm{~h}$ p.i. with PRRSV (arrows $=$ actin fibrils; $10 \mu \mathrm{m}$ ). (Length of scale bar is indicated for each panel) 
A

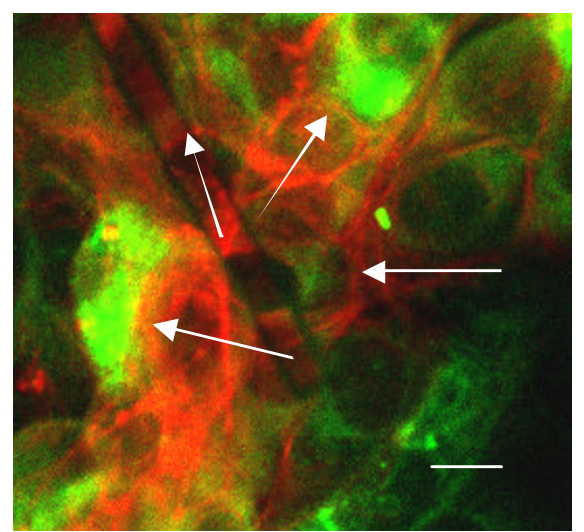

$\mathrm{D}$

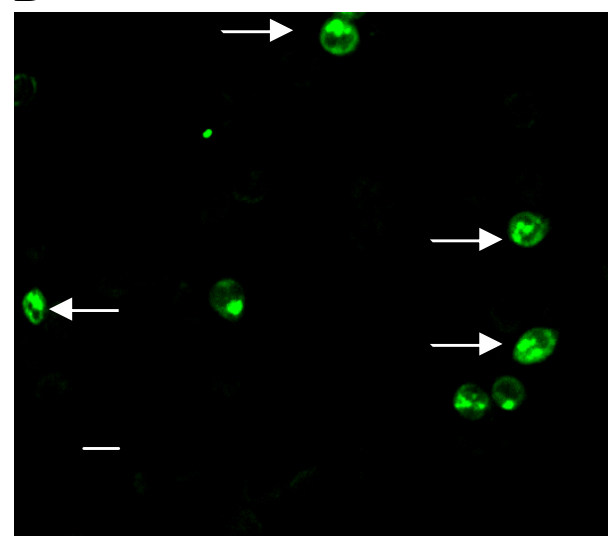

$\mathrm{B}$

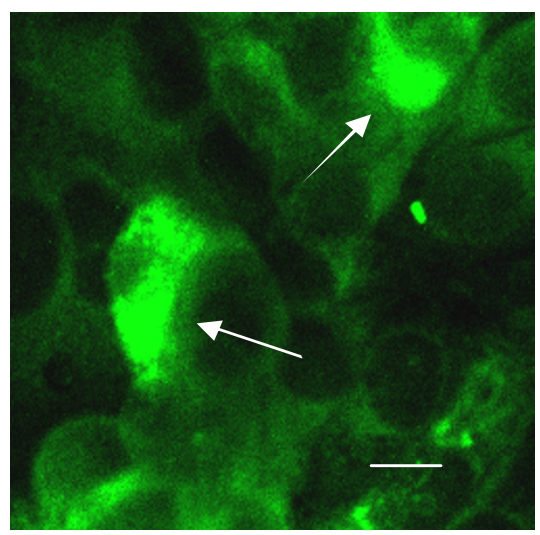

$\mathrm{E}$
$\mathrm{C}$
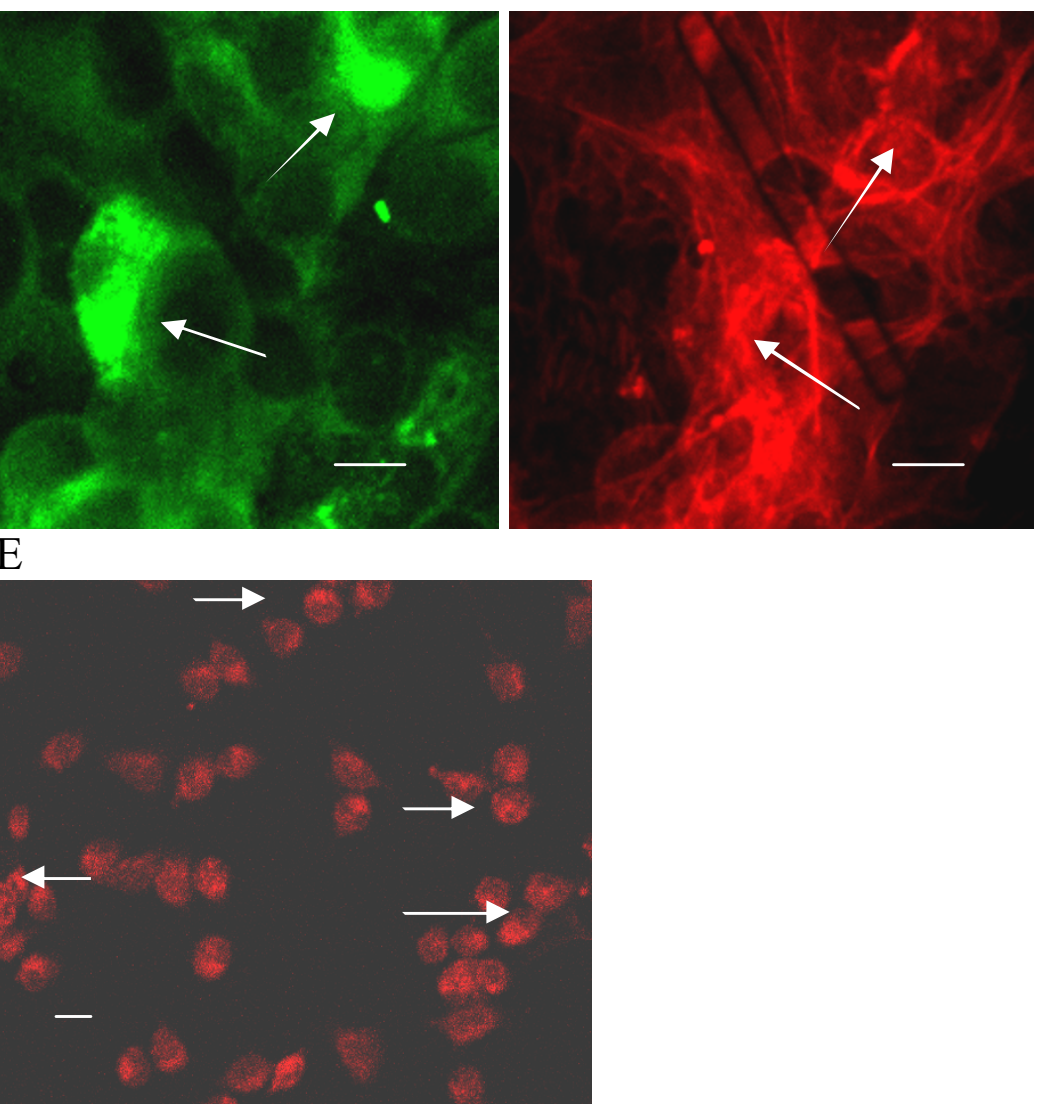

\section{Figure 7}

Two-color fluorescence detection of actin (red) and PRRSV antigen (green) in MARC-I 45 cells. A-C. Control 4 I h p.i.: A = actin (red) + PRRSV Ag (green); B = PRRSV Ag only; C = actin only; arrows = actin fibrils surrounding uninfected cells, $25 \mu \mathrm{m}$; D (LDV antigen) \& E (actin) expression in LDV-infected primary mouse macrophages; arrows indicate LDVinfected cells; $10 \mu \mathrm{m}$. (Length of scale bar is indicated for each panel).

Absence of cluster formation during primary infection did not appear to be due to insufficient M.O.I. or late-stage development of a soluble cluster-inducer during culture, since using up to about 100-times the standard virus dose (obtained from 45-96 h p.i. cell supernatants) did not induce cluster formation at 20-22 h p.i. in our experimental system (data not shown), and cluster formation was also density-dependent (see below - Figure 8B). Clusters of PRRSV-positive cells were maintained for up to $72 \mathrm{~h}$ p.i. as illustrated in Figure 3D, and images at this time were also suggestive of maintenance of central bright-staining cells as reservoirs of virus.

\section{Role of the cytoskeleton in PRRSV infection}

Treatment of cells with $10 \mu \mathrm{M}$ colchicine simultaneously with PRRSV inoculation, resulted in about $75 \%$ inhibition of secondary PRRSV infection (e.g. $70 \%$ in control vs. $18 \%$ in colchicine-treated culture; counting $>1000$ total cells at $46 \mathrm{~h}$ p.i.) and data representative of numerous experiments are shown in Figure 5E to illustrate the inhibitory effect of colchicine on formation of PRRSV-infected secondary clusters, which are seen spreading throughout the controls (Figure 5C,D). Similarly, exposure of cells to cytochalasin D under several experimental conditions (1 or $2 \mu \mathrm{M}$; administered either simultaneously with virus infection or $2 \mathrm{~h}$ pre-infection) inhibited PRRSV-positive cells by up to $87 \%$ (illustrated in Figure 8A between 1322 h p.i.; 2 h pre-treatment with $1 \mu \mathrm{M}$ ). These drug effects were confirmed by flow cytometric analyses (about 5090\% inhibition of PRRSV-positive cells; data not shown).

To further evaluate PRRSV transmission in vitro, actin expression was imaged using Alexa Fluor 594-phalloidin (red). Similar patterns of actin expression were observed in control uninfected (Figure 5A) and PRRSV-infected (Figure 5B) cells, and all cells expressed some degree of 
A

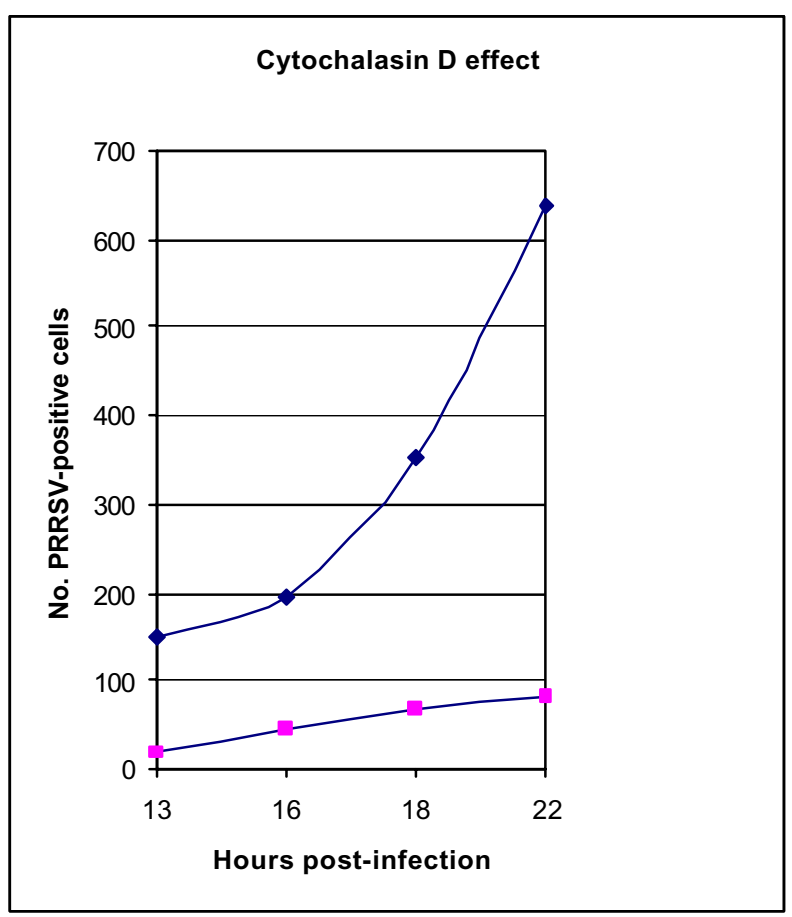

B

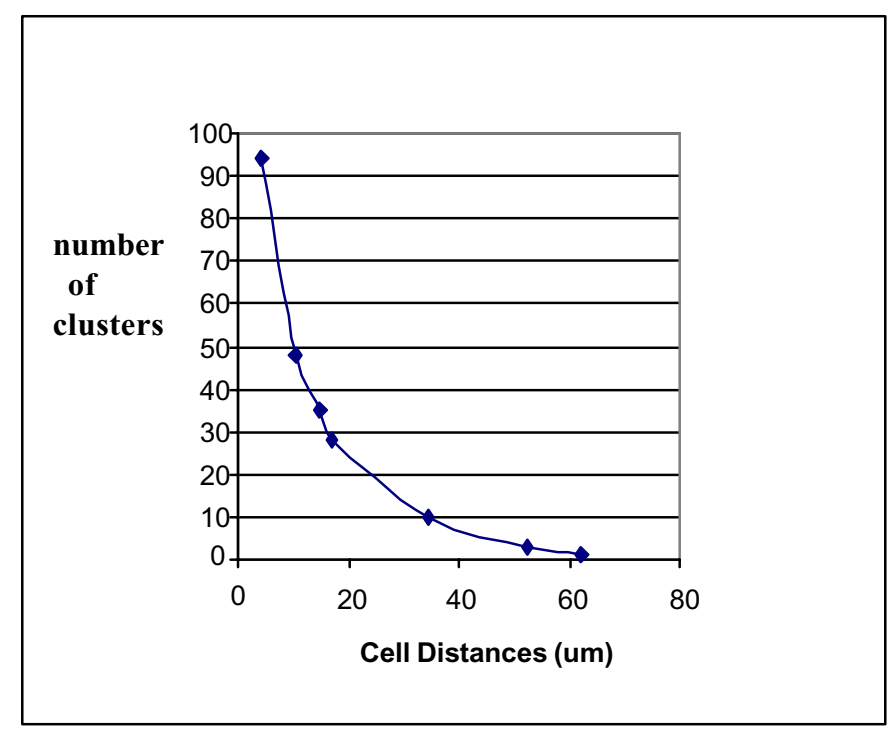

Figure 8

Time-course of PRRSV infection in cytochalasin D-treated ( $1 \mu \mathrm{m}$ pretreatment) and control MARC-I45 cells (A), and relationship of cell-to-cell distance and formation of secondary PRRSV-infected cell clusters (B). 
actin when high levels of gain were applied. Cells often displayed fibrillar actin extensions appearing along the outer membrane as well as less-elongated extensions over the body of the cell. Effects on the actin staining pattern were apparent after exposure of MARC-145 cells to the actin disruptor cytochalasin $\mathrm{D}$ (Figure $6 \mathrm{~F}$ ), and also to some extent after exposure to the microtubule inhibitor colchicine (Figure 5E) although intact actin fibrils were still present (see also description of Figure 6A,C,D below). Simultaneous determination of actin expression and PRRSV infection demonstrated that relatively high expression of actin filaments correlated with PRRSV resistance, which was a consistent finding in dozens of control- and colchicine-treated experiments. This observation is illustrated in Figure 6A, C, \&6D, where the arrows indicate the location of a PRRSV-positive doublet with low actin expression. Figures 5B and $6 \mathrm{E}$ also illustrate the negative correlation between actin and PRRSV-antigen expression. While this was not an absolute correlation (some PRRSVpositive cells did express high levels of actin), the trend was clear from $>5$ independent experiments. Actin fibrils also appeared to partition PRRSV-positive from PRRSVnegative cells and were often observed surrounding PRRSV-negative cells (Figures 6G and 7A-C; and see below). Cytochalasin D added at $18 \mathrm{~h}$ p.i. also suppressed secondary PRRSV-positive cluster formation (Figure 6F; $41 \mathrm{~h}$ p.i.; see emerging clusters in the control for this experiment Figure 6E), demonstrating a role for the cytoskeleton in cell-to-cell transmission.

The confluent cultures used in our experiments generally had mean cell-to-cell distances of $<2 \mu \mathrm{m}$, and the cells were usually in contact or too close to measure meaningful distances. Due to the wide dynamic range of the fluorescence signals, this is not always apparent in the figures, but some figures, such as $3 \mathrm{~A}, 7 \mathrm{~A} \& 7 \mathrm{~B}$, serve to illustrate the background of cultured cells. By seeding plates with different numbers of cells and then infecting these cultures containing different cell densities, it was possible to measure cell-to-cell distances in hundreds of cells per culture from the captured images, and then correlate the mean with the number of PRRSV-positive clusters (Figure $8 \mathrm{~B})$. The results show that formation of PRRSV-positive secondary clusters was density-dependent, with a direct correlation between the cell-to-cell mean distance and the number of clusters (Figure 8B).

In contrast to the ability of PRRSV to spread via cell-to-cell transmission, LDV did not exhibit this property, nor was there any dissociation of actin expression by primary cultured mouse macrophages from LDV permissiveness (probed during the replication peak, Figure 7D \&7E). Also in contrast to the response of PRRSV in MARC-145 cells, treatment of mouse macrophages with the same concentrations of colchicine had little effect on LDV replication
(+17\%, -26\%, and -21\% LDV-positive cells relative to control in three separate experiments), although LDV infection was completely suppressed by cytochalsin D (no LDV-positive cells detected in three separate experiments).

Combined, these data show that after primary acute PRRSV infection of a small subpopulation of PRRSV-permissive MARC-145 cells, the virus spreads secondarily over the next 2-3 days to surrounding cells by cell-to-cell transmission. These virus mechanisms are both actin- and tubulin-dependent, demonstrating the critical role of the cytoskeleton in the processes of PRRSV infection and spread. In contrast, the related arterivirus LDV displays no cell-to-cell transmission in primary culture mouse macrophages and primary LDV replication is not tubulindependent as revealed by absence of colchicine sensitivity.

\section{Suppression of PRRSV infection by targeting viral permissivness with AK-2 and IFN- $\gamma$}

Pretreatment of MARC-145 cells for about $18 \mathrm{~h}$ prior to PRRSV inoculation with AK-2 suppressed primary (Figure 2B) and secondary (Figure 2D) virus infection as assessed by flow cytometry. The pharmacodynamics of AK-2 inhibition of primary PRRSV infection were determined by microscopic FA analyses (Figure 9), demonstrating that the antiviral effect of AK-2 is on the PRRSV-permissive state rather than directly on the virus, since pretreatment was required to fully establish PRRSV resistance. No detectable morphological effects of AK-2 on MARC-145 cells were noted in our studies, and the PI profiles of treated cells were similar to those of control cells demonstrating intact and metabolically viable cells at 22-46 h p.i. (data not shown). AK-2 pretreatment completely inhibited the formation of secondary clusters of PRRSV infection, and only occasionally were single-positive cells observed at 42-46 h p.i. in AK-2-pretreated MARC-145 cells (Figures 3E \&4C). However, when added at $20 \mathrm{~h}$ p.i., AK-2 only partially inhibited secondary (cluster) PRRSV spread, although there was a shift to single-cell PRRSV infection (Figure 3F). Partial inhibition of secondary PRRSV infection by delayed AK-2 addition was also observed by flow cytometry, since AK-2 added at 18 h p.i. inhibited the $42 \mathrm{~h}$ p.i. expression of PRRSV antigen, by about one-half ( $27 \%$ vs. $58 \%$ in the drug-vehicle control; Figure 2F). Exposure of MARC-145 cells to AK-2 simultaneously with PRRSV inoculation suppressed all secondary cluster formation at $45 \mathrm{~h}$ p.i. (see control in Figure $4 \mathrm{E}$ and AK-2-treated in Figure 4F), confirming that, even without pretreatment, AK-2 can suppress the viral permissiveness of target cells for secondary cell-to-cell transmission, while leaving primary single-cell infection relatively intact due to the time required for induction of PRRSV resistance. 


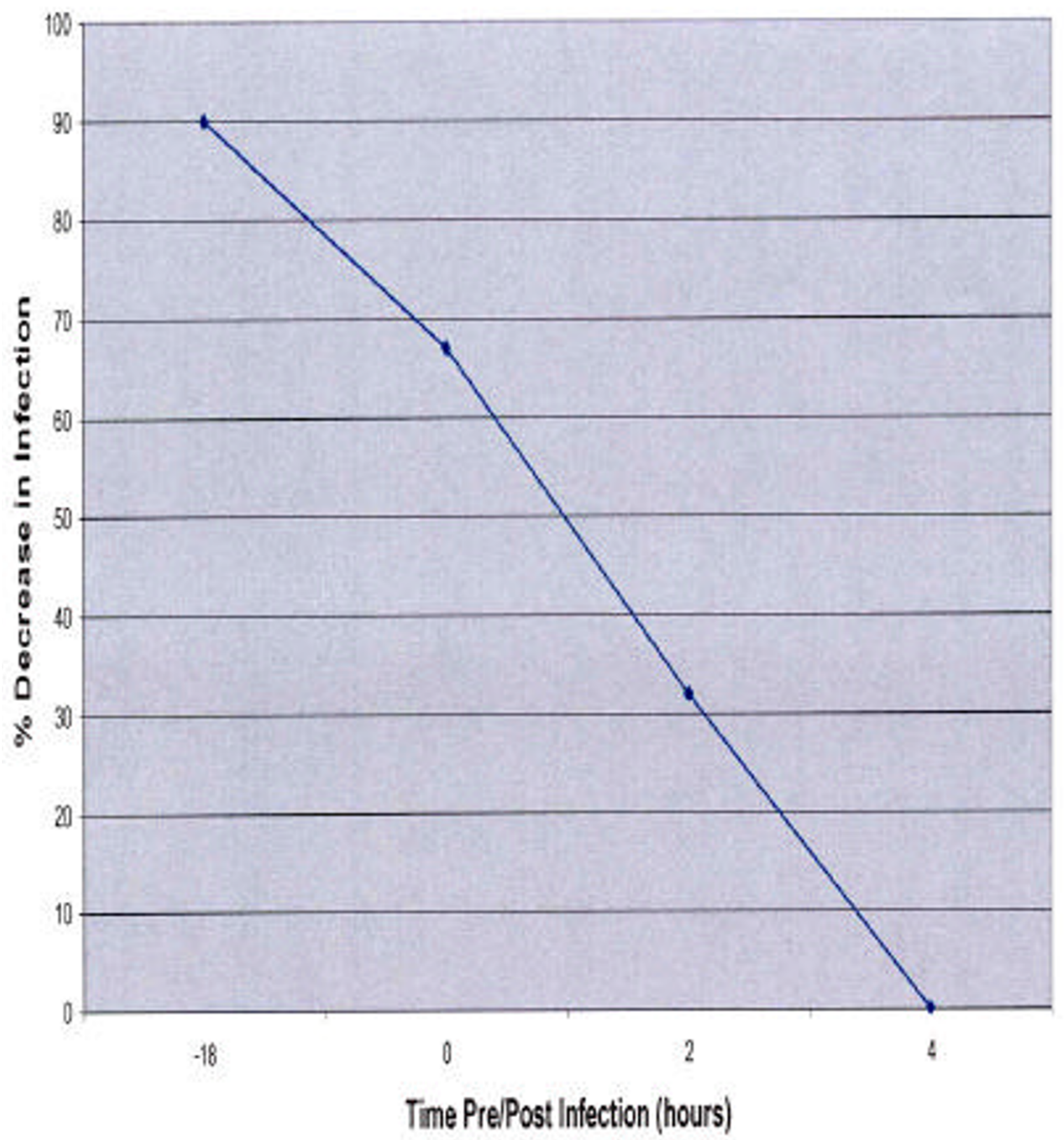

Figure 9

Pharmacodynamics of PRRSV inhibition by AK-2. MARC-I45 cells were exposed to AK-2 at various times pre- or postinfection. The \% inhibition of PRRSV antigen detection is shown on the y-axis. 
A higher-magnification image of AK-2-treated (single-cell infection only) is shown in Figure 5F, which also illustrates the often-observed appearance of actin fibrils surrounding a PRRSV-positive cell, as if to separate it from other uninfected cells as indicated above for Figure 6G. The data also show the absence of a detectable effect of AK-2 on actin expression.

In other studies, AK-2 pretreatment inhibited PRRSV antigen expression at $20-22 \mathrm{~h}$ p.i. by about $90 \%$ in primary pig macrophages, in each of two experiments. Similarly, pretreatment of primary mouse macrophages with recombinant murine AK-2 inhibited LDV replication by $86 \%$ in a single experiment. Thus, the anti-arterivirus effects of AK-2 are expressed over a broad host cell range.

Observations were also made for the anti-PRRSV effect of IFN- $\gamma$ pretreatment, which was demonstrated in previous studies to inhibit PRRSV replication [14]. PRRSV inhibition by IFN- $\gamma$ was less effective than that of AK- 2 under the same experimental conditions, as seen for example in the primary response to pretreatment measured by flow cytometry (Figure 2C,I); the effect of IFN- $\gamma$ pretreatment also waned by $40 \mathrm{~h}$ p.i. (Figure 2J). FA analyses confirmed the reduced efficacy of IFN- $\gamma$ relative to AK-2, since IFN- $\gamma$ pretreatment did not completely inhibit formation of secondary PRRSV antigen-positive clusters (Figure 4A,D) and there were higher numbers of PRRSV antigen-positive cells in IFN- $\gamma$-pretreated cultures (data not shown). Consistent with these data, flow cytometry demonstrated that IFN- $\gamma$ added at $18 \mathrm{~h}$ p.i. had a reduced effect on secondary PRRSV infection (Figure 2G), relative to AK-2 (Figure 2F) or the combination of AK2 and IFN- $\gamma$ (Figure $2 \mathrm{H}$ ); the inhibitory effect of post-treatment with both drugs is also shown in Figure $2 \mathrm{H}$, although little if any synergy was observed. Thus, while IFN- $\gamma$ mediated significant inhibition of PRRSV infection, AK-2 appears to be a more potent anti-PRRSV agent.

\section{Discussion}

The results of this study show that PRRSV replication in an experimental MARC-145 cell system is composed of two discrete phases: primary infection of a relatively small subpopulation of PRRSV-permissive cells during about the first $22 \mathrm{~h} \mathrm{p.i,} \mathrm{followed} \mathrm{by} \mathrm{secondary} \mathrm{cell-to-cell} \mathrm{spread}$ over the next several days to contiguous cells, resulting in formation of infected cell clusters and ultimately cell death/CPE by days 3-4 p.i. Flow cytometry of PRRSV infection of pig macrophages has previously been reported [32], but for the present study we developed a flow technique to quantitatively measure PRRSV antigen expression in MARC-145 cells, a standard cell line for the study of PRRSV infection. Combined with FA analyses by microscopy, this methodology provides evidence that permissiveness to PRRSV infection is dependent on the mechanism of virus presentation, since the majority of cells appear non-permissive to free virus, but become readily infected by exposure to productively-infected cells.

These dynamics of PRRSV infection of MARC-145 cells stand in stark contrast to those of the related and relatively benign arterivirus LDV, since primary LDV infection of cultured mouse macrophages peaks at about $8 \mathrm{~h}$ p.i. in vitro, and soon thereafter in vivo, but there is little or no secondary virus replication after these events [17]. A likely explanation for this difference is the absence of cell-to-cell (cluster) spread of LDV. The ability of PRRSV to spread secondarily by cell-to-cell transmission may overcome an early block to virus permissiveness, and while it is not yet known whether this mechanism occurs in vivo, it could potentially help PRRSV resist antibody defenses and maintain persistence.

Our studies show that PRRSV transmission to infected cell clusters is dependent upon cytoskeletal function, since the microtubule inhibitor colchine [26-28] as well as the actin inhibitor cytochalasin D [26,29-31] suppressed secondary virus spread. Consistent with this conclusion, a number of other viruses are dependent on the host cytoskeleton for entry, transport, and/or egress [32-34], and actin polymerization may enhance cell-to-cell virus spread [35]. For example, the actin cytoskeleton is a critical factor for assembly and/or budding of HIV-1 [36], West Nile virus [37], respiratory syncytial virus [31], fowlpox virus [38], and equine infectious anemia virus [39]. Interestingly, we observed that the pattern of actin expression correlated with PRRSV resistance, since there was often a distinct appearance of actin filaments surrounding PRRSV-negative cells, and a general (but not absolute) negative correlation between viral antigen detection and the level of actin expression. This finding appears to suggest that actin provides a protective barrier to cell-to-cell transmission, and that the actin cytoskeleton may have a dual role in PRRSV infection. This seemingly paradoxical observation may be analogous to that reported for transport of secretory granules, which is both limited and mediated by the actin cortex [40]. Furthermore, the actin cytoskeleton is a potential barrier to exocytosis $[41,42]$, and the cortical actin network may provide a cellular barrier to SFV [43] and HIV [29]. PRRSV infection might potentially inhibit the cytoskeleton [44-46], to further promote virus spread in culture. In contrast to the finding with PRRSV, there was no difference between actin expression in LDV-permissive and LDV-non-permissive mouse macrophages. Additional studies of the role of the cytoskeleton should be of interest to PRRSV pathogenesis and the biology of arteriviruses.

Primary infection was dependent on an intact cytoskeleton, and nascent cluster initiation during this time frame 
was signified by the occasional appearance of infected cell doublets. Formation of secondary PRRSV-infected cell clusters was a function of time p.i. and the cell-to-cell distance, and is thus a physical property of the in vitro system, potentially analogous to tissue sites in vivo. The viral dynamics from our studies are consistent with previous observations demonstrating infection of a small percentage of cells by day 1 p.i., which increases markedly over the next few days, culminating in peak supernant virus titers at about 72-96 h p.i. [9]. The data also suggest that 1 $\mathrm{TCID}_{50}$ contains multiple virions since the number of cells acutely infected can exceed the TCID ${ }_{50}$ dose and optimal infection is achieved at low M.O.I. (calculated by TCID ${ }_{50}$ ) as previously reported $(9,14)$. Future studies to clarify the relationship of M.O.I and TCID ${ }_{50}$ might help to determine what special characteristics facilitate primary permissiveness to free virus, which could include ability to bind one or more virions as well as biochemical factors regulating virus replication.

Our data show that the logarithmic increase in the percentage of PRRSV infected cells over about 2-4 days p.i. is due to secondary cell-to-cell virus spread, from innatelypermissive (reservoir) cells to surrounding uninfected cells. The foci of infection typically observed microscopically, in cultures of PRRSV-infected cells which begin to degenerate by 3-4 days p.i., are thus the outcome of secondary cluster infection and direct virus infection. These data reinforce that secondary spread to clusters in MARC145 cells provides an important direction for future studies of PRRSV mechanisms, since cell-to-cell virus transmission [47] might help to explain the resistance of PRRSV to antibody-mediated control as well as PRRS pathology. In a recent study, the replication of PRRSV in transformed pig peripheral blood monocytes was shown to be under genetic control and varied between $23.1-31.4 \%$ at $24 \mathrm{~h}$ p.i. [48]. Thus, our results suggest the possibility that variations in cell-to-cell PRRSV transmission may underlie differences in PRRSV replication between different cell lines in vitro.

The present results show that AK-2 is a potent inhibitor of arterivirus (PRRSV and LDV) replication. This is the first published report of the antiviral effects of AK-2, which suppresses viral permissiveness by activating an antiviral gene program (Wong; unpublished), and which we exploited to supplement our studies of the IFN- $\gamma$ response. Pretreatment was required for full expression of the drug effects, likely due to a lag phase for activation of the antiviral gene program. Both primary as well as secondary (cluster) PRRSV infection were susceptible to the antiviral actions of AK-2, but required optimal conditions of pretreatment for induction of the PRRSV-resistant state, and secondary PRRSV infection was controlled independently of primary infection by simultaneous or delayed drug exposure. IFN- $\gamma$ was relatively less effective under our experimental conditions, but our IFN- $\gamma$ data reinforce the conclusion that the viral-permissive state is an important drug target in PRRSV infection. This is also the case for LDV-mediated fetal infection $[49,50]$ and neuropathology [51], since suppression of LDV-permissiveness by IFN $-\gamma$ reduces these viral phenomena, and the arteriviruses may be good models for the role of permissiveness in antiviral strategies. Despite sensitivity to IFN- $\alpha$, PRRSV may be a relatively weak inducer of this cytokine [52], facilitating evasion of host defenses. Thus, development of useful drugs which target viral permissiveness could be a superior strategy to inhibit primary or secondary phases of PRRSV infection, particularly if secondary cell-to-cell spread is resistant to a conventional antibody attack, and might also provide a superior toxicity profile, since the induction of PRRSV resistance is fundamentally a physiological process.

\section{Conclusion}

PRRSV infection has been shown to spread by cell-to-cell transmission in a stable MARC-145 cell line. Two stages of viral infection have been identified: primary (innate) permissiveness to free-virus which appears in a relatively small percentage of cells, and secondary permissiveness to cell-to-cell transmission which is highly expressed and culminates in CPE. PRRSV infection of MARC-145 cells requires an intact cytoskeleton, but actin expression may also correlate with cell protection. Drugs such as AK-2 which induce a block in PRRSV permissiveness reveal a potentially important drug target for suppression of primary and secondary PRRSV infection.

\section{Methods \\ MARC-I45 cells}

A stable and mycoplasma-free MARC-145 cell line was utilized in these experiments. Cells were cultured in DMEM containing $10 \%$ fetal bovine serum, and for virus infections the medium was switched to MEM containing $2 \%$ horse serum. Cells for virus infections were grown to confluency in either T-25 flasks (seeded with about $5 \times$ $10^{5}$ cells/culture) or 8 -well glass slide chambers (seeded with about 10,000 cells/culture; Lab-Tek II; Nalge Nunc International), and for the cell density studies, serial twofold dilutions of the cells were used. Cells were inoculated with PRRSV at about 1-2 days after seeding (time to approximate doubling of the population).

\section{Primary pig macrophages}

Pig cells were collected from 4-8 week old pigs by lung lavage with PBS [21-23]. Cells were cultured in DMEM containing 10\% FBS. After 18-24 h, non-adherent cells were removed by washing. The remaining adherent cells were cultured for an additional $24 \mathrm{~h}$ in RPMI containing 
2\% horse serum, and then inoculated with PRRSV (M.O.I. approximately $0.1 \mathrm{TCID}_{50}$ ).

\section{PRRSV stocks}

PRRSV isolate SD-23983 was passaged on MARC-145 cells, preparing high-titer $\left(\sim 10^{5} \mathrm{TCID}_{50}\right.$ per $\left.\mathrm{ml}\right)$ virus stocks from culture supernatants at $48-96 \mathrm{~h}$ p.i. PRRSV stocks were sequentially filtered through $0.45,0.22$, and 0.10 um filters and confirmed to be mycoplasma-free by testing on PPLO medium. As reported previously $(9,14)$, maximum efficiency of PRRSV infection of MARC-145 cells occurs with low M.O.I as determined by TCID ${ }_{50}$ probably due to the presence of multiple virions per $\mathrm{TCID}_{50}$. For the present studies, M.O.I. of about 0.01 $\mathrm{TCID}_{50}$ (slide cultures) and $0.001 \mathrm{TCID}_{50}$ (T-flask cultures) were found to result in near-optimal efficiency of infection, and were thus used for our studies unless otherwise noted in Results.

\section{Fluorescence (FA) detection of viral and cellular target molecules}

PRRSV replication was detected using FITC-labeled IgG anti-PRRSV nucleocapsid monoclonal antibody (SDOW17; [24]). MARC-145 cells were cultured and inoculated with PRRSV in glass-bottom slide chambers, fixed in $80 \%$ acetone, and incubated for $1 \mathrm{~h}$ at $37^{\circ} \mathrm{C}$ with a 1:100 dilution of FITC-conjugated SDOW17 antibody made in PBS containing 5\% fetal bovine serum. Then the cells were washed three times with cold PBS prior to examination under a fluorescence microscope, screening about $30-40,000$ total cells to obtain the incidence of antigenpositive cells. Confocal fluorescence microscopy was performed using an Olympus BX61 microscope and Fluoview software. Images shown in Figures 3 and 4 display the yellow scale bar captured with the original image, along with a higher-contrast white scale line. For flow cytometry, MARC-145 cells were cultured and PRRSVinoculated in T-flasks, the cells were suspended in trypsinversene, pelleted at $1000 \mathrm{rpm}$, resuspended in DMEM with $2 \%$ horse serum, fixed in cold $80 \%$ acetone for 10 min, washed twice in PBS, and resuspended in $1 \mathrm{ml}$ PBS containing $60 \mathrm{ul}$ of fetal bovine serum. FITC-conjugated SDOW17 antibody was then added to the cells $(2.5 \mathrm{ul} /$ $\mathrm{ml}$ ), incubation was carried out at $37^{\circ} \mathrm{C}$ for $60 \mathrm{~min}$, the cells were washed with PBS, examined under a fluorescence microscope, and flow cytometry was performed with a FACSVantage SE (Becton Dickenson) equipped with a 488 Enterprise II coherent laser. Twenty thousand events per sample were analyzed with CellQuest software. Cell cycle analyses were also performed on the same samples, by staining with propidium iodide for 20 minutes at room temperature and analyzing the flow cytometric results with ModFit LT 2.0 software. PRRSV replication in primary pig alveolar macrophages $[22,23]$ was assessed by FA under a fluorescent microscope. Cellular expression of actin was determined by incubating acetone-fixed cells with AlexaFluor 594 phalloidin (Invitrogen) according to the manufacturer's instructions, with the modification of simultaneous PRRSV detection as above, such that combined labels were applied for $60 \mathrm{~min}$ at $37^{\circ} \mathrm{C}$, permitting two-color fluorescence detection by confocal microscopy. Data shown are representative of at least 2 replicate experiments for each type of experiment described in the Results.

\section{LDV infection of primary mouse macrophages}

Peritoneal macrophages were collected from outbred ICR mice, seeded onto glass coverslips, and inoculated with a standard dose of LDV-P as described previously [25]. LDV replication was assessed in cells fixed in acetone at $8 \mathrm{~h}$ p.i by IFA assay as described previously [25].

\section{Drug treatments}

Purified recombinant human interferon- $\gamma$ (IFN- $\gamma ; 100 \mathrm{ug} /$ $\mathrm{ml}$ ) and actokine-2 (AK-2; $50 \mathrm{ug} / \mathrm{ml}$ ) were provided by Actokine Therapeutics. AK-2 is a cytokine-based experimental antiviral being developed by Actokine Therapeutics, which consists of recombinant normal human proteins comprising part of the mammalian cell response to virus infection (Wong; unpublished). Soluble stocks of these agents were stored at $4^{\circ} \mathrm{C}$ in fetal bovine serum, which also served as the drug-vehicle control for the experiments, and were diluted 1:50 or 1:100 in medium to yield concentrations in cell cultures of about 1-2 ug/ $\mathrm{ml}$. As noted for individual experiments, cells were exposed to the drug or control treatments prior to PRRSV infection (pretreatment), during the course of PRRSV infection (delayed or post-treatment), or simultaneously with PRRSV infection. Based on previous studies of in vitro efficacy, the microtubule inhibitor colchicine which binds to tubulin (Sigma; 5 or $10 \mu \mathrm{M} ; 26-28$ ) or the microfilament disruptor cytochalasin $\mathrm{D}$ which depolymerizes actin (Sigma; 1 or $2 \mu \mathrm{M}$; [26,29-31]) were added to cell cultures at the times indicated.

\section{Competing interests}

The author(s) declare that they have no competing interests.

\section{Authors' contributions}

WAC conceived and designed the study, carried out experiments, performed data collection and analyses, and drafted the manuscript. RGD was responsible for cell culture, carried out some of the fluorescence analyses, and contributed to the FACS analyses. GHW prepared AK-2, IFN- $\gamma$, and control reagents and contributed to the experimental design. SS performed the FACS analyses. PWD carried out infection assays and performed some of the manual microscopic analyses. RRRR prepared pig macrophages, MARC-145 cells, and PRRSV for the project. EAN 
prepared the antibody reagent, MARC-145 cells, and PRRSV for the project. All authors made intellectual contributions to the study, and participated in the review and revision of the manuscript.

\section{Acknowledgements}

This research was supported by a grant from the Center for Infectious Disease Research and Vaccinology (WAC) and an internal summer medical student research stipend (PWD). We thank Dr. Fran Day for assistance with microscopy, and Debdutta Mukherjee and Megan Hora for microscopic analyses.

\section{References}

I. Albina E: Epidemiology of porcine reproductive and respiratory syndrome (PRRS): an overview. Vet Microbiol 1997 55:309-16.

2. Meng $X \mathrm{~J}$ : Heterogeneity of porcine reproductive and respiratory syndrome virus: implication for current vaccine efficacy and futurevaccine development. Vet Microbio 2000, 74:309-329.

3. Prieto $C$, Castro JM: Porcine reproductive and respiratory syndrome virus infection in the boar: a review. Theriogenology 2005, 63:1-16.

4. Wills RW, Zimmerman JJ, Yoon KJ, Swenson SL, McGinley MJ, Hill HT, Platt KB, Christopher-Hennings J, Nelson EA: Porcine reproductive and respiratory syndrome virus: a persistent infection. Vet Microbiol 1 997, 55:23I-240.

5. Thanawongnuwech R, Halbur PG, Thacker EL: The role of pulmonary intravascular macrophages in porcine reproductive and respiratory syndrome virus infection. Anim Health Res Rev 2000, I:95-102.

6. Murtaugh MP, Xiao Z, Zuckermann F: Immunological responses of swine to porcine reproductive and respiratory syndrome virus infection. Viral Immunol 2002, 15:533-47.

7. Kim HS, Kwang J, Yoon IJ, Joo HS, Frey ML: Enhanced replication of porcine reproductive and respiratory syndrome (PRRS) virus in a homogeneous subpopulation of MA- 104 cell line. Arch Virol 1993, 133:477-483.

8. Meulenberg J]: PRRSV, the virus. Vet Res 2000, 3 I (I):| |-2|

9. Kim TS, Benfield DA, Rowland RRR: Porcine reproductive and respiratory syndrome virus-induced cell death exhibits features consistent with a non-typical form of apoptosis. Virus Res 2002, 85: I33-140.

10. Miller LC, Fox JM: Apoptosis and porcine reproductive and respiratory syndrome virus. Vet Immunol Immunopathol 2004, 102:131-142.

II. Thanawongnuweh R: Interleukin-10, Interleukin-12, and Interferon- $\gamma$ levels in the respiratory tract following mycoplasma hyopneumonia and PRRSV infection in pigs. Viral Immunol 2003, 16:357-67.

12. Johnsen CK, Botner A, Kamstrup S, Lind P, Nielsen J: Cytokine mRNA profiles in bronchoalveolar cells of piglets experimentally infected in utero with porcine reproductive and respiratory syndrome virus: association of sustained expression of IFN-gamma and IL- 10 after viral clearance. Viral Immunol 2002, I 5:549-56

13. Aasted B, Bach P, Nielsen J, Lind P: Cytokine profiles in peripheral blood mononuclear cells and lymph node cells from piglets infected in utero with porcine reproductive and respiratory syndrome virus. Clin Diag Lab Immunol 2002, 9:1229-I234.

14. Rowland RR, Robinson B, Stefanick J, Kim TS, Guanghua L, Lawson $S R$, Benfield DA: Inhibition of porcine reproductive and respiratory syndrome virus by interferon-gamma and recovery of virus replication with 2-aminopurine. Arch Virol 200I, 146:539-55.

15. Meier WA, Galeota J, Osorio FA, Husmann RJ, Schnitzlein WM, Zuckermann FA: Gradual development of the interferongamma response of swine to porcine reproductive and respiratory syndrome virus infection or vaccination. Virol 2003 , 309:|8-3|

16. Meier WA, Husmann RJ, Schnitzlein WM, Osorio FA, Lunney JK, Zuckermann FA: Cytokines and synthetic double-stranded RNA augment the $T$ helper $I$ immune response of swine to porcine reproductive and respiratory sundrome virus. Vet Immunol Immunopathol 2004, 102:299-3I4.

17. Plagemann PGW, Moennig V: Lactate dehydrogenase-elevatingvirus, equine arteritis virus, and simian hemorrhagic fever virus: a new group of positive-strand RNA viruses. Adv Virus Res 1992, 41:99-192.

18. Durbin JE, Fernandez-Sesma A, Lee CK, Rao TD, Frey AB, Moran TM, Vukmanovic S, Garcia-Sastre A, Levy DE: Type I IFN modulatesinnate and specific antiviral immunity. J Immunol 2000, 164:4220-4228.

19. Basler CF, Garcia-Sastre A: Viruses and the type I interferon antiviral system: induction and evasion. Internat Rev Immunol 2002, $21: 305-7$

20. Freihorst J, Ogra PL: Mucosal immunity and viral infections. Ann Med 200I, 33:172-7.

21. Mengeling WL, Lager KM, Vorwald AC: Diagnosis of porcine reproductive and respiratory syndrome virus. J Vet Diagn Invest 1995, 7:3-16.

22. Duan $X$, Nauwynck HJ, Pensaert MB: Effects of origin andstate of differentiation and activation of monocytes/macrophages on their susceptibility to porcine reproductive and respiratory syndrome virus PRRSV. Arch Virol 1997, I 42:2483-2497.

23. Oleksiewicz MB, Nielsen J: Effect of porcine reproductive and respiratory syndrome virus (PRRSV) on alveolar lung macrophagesurvival and function. Vet Mircobiol 1999, 66:15-27.

24. Nelson EA, Christopher-Hennings J, Drew T, Wensvoort G, Collins JE, Benfield DA: Differentiation of U.S. and European isolates of porcine reproductive and respiratory syndrome virus by monoclonal antibodies. I Clin Microbiol I993, 31:3 |84-3 I89.

25. Cafruny WA, Chen SP, Harty JT, Yousefi S, Kowalchyk K, McDonald $D$, Foreman B, Budweg G, Plagemann PGW: Antibody response of mice to lactate dehydrogenase-elevating virus during infection and immunization with inactivated virus. Virus Res 1986, 5:357-375.

26. Gregoraszczuk EL, Stoklosowa S: The effect of microtubule and microfilament-disrupting drugs on prolactin-stimulated progesterone synthesis and secretion by cultured porcine theca cells. Acta Histochem 1997, 99:207-I5.

27. Taylor EW: The mechanism of colchine inhibition of mitosis: I. Kinetics of inhibition and the binding of $\mathrm{H}^{3}$-colchicine. J Cell Biol 1965, 25:145-160.

28. Shibaya M, Deptula KM, Korzekwa A, Kiyoshi O, Skarzynski DJ: Involvement of the cytoskeleton in ocytocin secretion by cultured bovine luteal cells. Biol Reprod 2005, 72:200-205.

29. Campbell EM, Nunez R, Hope TJ: Disruption of the actin cytoskeleton can complement the ability of Nef to enhance human immunodeficiency virus type I infectivity. J Virol 2004 78:5745-5755.

30. Wakatsuki T, Schwab B, Thompson NC, Elson EL: Effects of cytochalasin D and lantriculin B on mechanical properties of cells. / Cell Science 200I, I I 4:1025-36.

3I. Kallewaard NL, Bowen AL, Crowe JEJ: Cooperativity of actin and microtubule elements during replication of respiratory syncytial virus. Virol 2005, 331:73-8I.

32. Thacker EL, Halbur PG, Paul PS, Thacker BJ: Detection of intracellular porcine reproductive and respiratory syndrome virus nucleocapsid protein in porcine macrophages by flow cytometry. J Vet Diagn Invest 1998, 10:308-3। I.

33. Sodeik B: Mechanisms of virus transport in the cytoplasm. Trends Microbiol 2000, 8:465-472.

34. Han A, Harty RN: Packaging of actin into Ebola virus VLPs. Virol J 2005, 2:92-99.

35. Newsome TP, Scaplehorn N, Way M: Src mediates a switch from microtubule-to actin-based motility of vaccinia virus. Science 2004, 306(5693): 124-129.

36. Sasaki H, Nakamura M, Ohno T, Matsuda $Y$, Yuda $Y$, Nonomura $Y$ : Myosin-actin interaction plays an important role in human immunodeficiency virus type I release from host cells. Proc Natl Acad Sci USA 1995, 92:2026-2030.

37. Chu J], Choo BG, Lee JW, Ng ML: Actin filaments participate in Wets Nile (sarafend) virus maturation process. J Med Virol 2003, 71:463-472.

38. Boulanger D, Smith T, Skinner MA: Morphogenesis and release of fowlpox virus. J Gen Virol 2000, 8 I:675-687. 
39. Chen C, Weisz OA, Stolz DB, Watkins SC, Montelaro RC: Differential effects of actin cytoskeleton dynamics on equine infectious anemia virus particle production. J Virol 2004, 78:882-89I

40. Lang T, Wacker I, Wunderlich I, Rohrbach A, Giese G, Soldati T, Almers W: Role of actin cortex in the subplasmalemmal transport of secretory granules in PC-12 cells. Biophys J 2000, 78:2863-2877.

41. Chowdhury HH, Popoff MR, Zorec R: Actin cytoskeleton and exocytosis in rat melanotrophs. Pfluggers Arch - Euro J Physio 2000, 439(3S):RI48-I49.

42. Trifaro JM, Rodriguez del Castillo A, Vitale ML: Dynamicchanges in chromaffin cell sytoskeleton as prelude to exocytosis. Mol Neurobiol 1992, 6:339-58.

43. Marsh M, Bron R: SFV infection in CHO cells: cell-typespecific restrictions to productive virus entry at the cell surface. J Cell Sci 1997, I 1 0:95-103.

44. Kuhn M, Desloges N, Rahaus M, Wolff MH: Varicella-zoster virus infection influences expression and organization of actin and $\alpha$-tubulin but does not affect lamin $A$ and vimentin. Intervirol 2005, 48:3।2-320.

45. Meyer RK, Burger MM, Tschannen R, Schafer R: Actin filament bundles in vaccinia virus infected fibroblasts. Arch Virol 1981, 67: II-18.

46. Ploubidou A, Moreau V, Ashman K, Reckman I, Cayetano G, Way M: Vaccinia virus infection distrupts microtubule organization and centrosome function. EMBO J 2000, 19:3932-3944.

47. Johnson DC, Huber MT: Directed egress of animal viruses promotes cell-to-cell spread. J Virol 2002, 76: I-8.

48. Vincent AL, Thacker BJ, Halbur PG, Rothschild MF, Thacker EL: An investigation of susceptibility to porcine reproductive and respiratory syndrome virus between two genetically diverse commercial lines of pigs. J Anim Sci 2006, 84(I):49-57.

49. Haven TR, Rowland RRR, Plagemann PGW, Wong GHW, Bradley SE, Cafruny WA: Regulation of transplacental virus infection by developmental and immunological factors: studies with lactate dehydrogenase-elevating virus. Virus Res 1996, 41:153-160.

50. Zitterkopf NL, Haven TR, Huela M, Bradley DS, Cafruny WA: Transplacental lactate dehydrogenase-elevating virus transmission: immune inhibition of umbilical cord infection, and correlation of fetal virus susceptibility with development of F4/80 antigen expression. Placenta 2002, 23:438-446.

51. Cafruny WA, Haven TR, Lawson SR, Wong GHW, Rowland RRR: Inhibition of virus-induced age-dependent poliomyelitis by interferon- $\gamma$. Antiviral Res 1997, 36: I-9.

Publish with Bio Med Central and every scientist can read your work free of charge

"BioMed Central will be the most significant development for disseminating the results of biomedical research in our lifetime. "

Sir Paul Nurse, Cancer Research UK

Your research papers will be:

- available free of charge to the entire biomedical community

- peer reviewed and published immediately upon acceptance

- cited in PubMed and archived on PubMed Central

- yours - you keep the copyright
BioMedcentral 